\title{
The influence of paving-block shape on the infiltration capacity of permeable paving
}

\author{
D. Castro, N. González-Angullo, J. Rodríguez and M.A. Calzada
}

\begin{abstract}
This paper reports on an investigation into the effects of the shape of concrete paving blocks used in permeable pavements. It describes a series of hydraulic performance tests on blocks with different drainage slot geometries, in order to determine their influence on infiltration capacity. Paving samples were tested in a purpose-designed laboratory rig consisting of a variable-gradient testing frame, rain simulator and water-collecting chambers. The apparatus allowed for slope variations and two inputs of water: input runoff and direct rainfall over the surface. Four differently shaped slotted concrete blocks were tested under three different clogging states and four gradients. The results obtained lead to initial conclusions about the influence of block geometry on the hydraulic performance of paving which have implications for pavement design.
\end{abstract}

Key words: best management practices, clogging; drainage path, pavements, permeable, sustainable urban drainage systems

\section{INTRODUCTION}

Pervious pavements are an important subset of SUDS (sustainable urban drainage systems) and BMPs (best management practices) (Pratt et al. 2002). Pervious surfaces can be divided into porous and permeable pavements. Permeable pavements are surfaced with nonporous materials that enable water to filter through inlets or slots in the surface (Pratt 1997). In the case of permeable paving using concrete blocks, these slots can be created in the blocks during the manufacturing process.

Normally, applications of pervious paving are restricted to low-volume parking areas, although they

Received November 2006; accepted February 2007

Authors

D. Castro, ${ }^{*}$ N. González-Angullo, J. Rodríguez and M.A.

Calzada, Departamento de Transportes y T. de P. y P.

ETSICCP, Universidad de Cantabria, Avd. los Castros s/n, 39005 Santander, Spain

${ }^{*}$ Corresponding author. Tel. +34 942202053, fax +34

942201703, email daniel.castro@unican.es can tolerate runoff from rooftop storage or adjacent conventionally paved areas. Such surfaces have a high removal capacity with regard to soluble and fine particulate pollutants in urban runoff, as well as allowing groundwater recharge and stream bank erosion control (Novotny and Olem 1994). Some other advantages of pervious surfaces are: reduced land requirements; the reduction or elimination of downstream conveyance systems; the preservation of the natural water balance at the site; and the provision of surfaces with improved skid resistance, which reduces hydroplaning (Schueler 1987).

Due to their filtration characteristics, pervious pavements cannot be used in areas where hazardous substances are likely to be washed into the subsoil. Besides, their use may be restricted in cold or arid regions; regions with high wind erosion; and areas of sole-source aquifers. In normal circumstances, however, the most common factor causing failure of pervious surfaces is 'clogging'.

Clogging can be defined as the accumulation of silt within the pavement structure, due to sedimentation, 
thus reducing the filtering capacity of the pavement (Dierkes et al. 2002). This blockage of the pavement is most likely to occur in the surface layers and in the geotextile layers, if these are used (Rommel et al. 2001).

The main aims of this work were to test the hypothesis that the geometrical design of the concrete blocks affects the hydraulic performance of the permeable pavement, and to determine the most efficient block geometry under various conditions of gradient and clogging. The specific objectives were to propose alternative paving-block geometries, and to test and compare their hydraulic performance.

The hydraulic performance study was carried out using a specifically designed test based on previous experience (Rommel et al. 2001; Davies et al. 2002; Rodríguez et al. 2005), trying to develop a protocol for testing permeable surfaces in order to analyse the effects of clogging and gradient.

\section{MATERIALS AND METHODS}

\section{Apparatus}

The apparatus used is designed to test the drainage capacity of a pavement sample of $500 \mathrm{~mm}$ width and $500 \mathrm{~mm}$ length. The apparatus, shown in Figure 1, consists of a testing frame, grid, water-collecting chambers and rain simulator.

The steel testing frame has four legs supporting a grid on which the samples are placed. The frame can be adjusted to test the samples using different gradients. Five chambers collect the water that is filtered through the sample. These filter chambers are of equal size and are placed parallel to the downward gradient, so that chamber 1 is the chamber located below the highest section of the sample and chamber 5 is located below the lowest section of the sample. Runoff water is collected in chamber 6 .

The rain simulator is designed to water the sample with two types of irrigation. A transversal pipe is located at the highest part of the apparatus which provides a curtain of rain to produce runoff. There are also five parallel pipes with sprinklers that produce raindrops directly over the sample. Both sources of rain have independent, adjustable flows.

\section{Pavement samples}

The samples of permeable pavement analysed consisted of a layer of geotextile bedding, a granular base and concrete blocks (Figure 2).

The geotextile plays a fundamental role in the pavement structure. It is used as separation, filter or reinforcement (Pratt 2003). The geotextile selected for this test was non-woven polyester of $150 \mathrm{~g} / \mathrm{m}^{2}$, with a water permeability flow rate of $110 \mathrm{~L} / \mathrm{m}^{2} \mathrm{~s}$.

The granular base was placed on top of the geotextile. This was of limestone, $50 \mathrm{~mm}$ deep, handcompacted and levelled. The particle sizes were between $4 \mathrm{~mm}$ and $6.35 \mathrm{~mm}$ diameter after sieving (Rodríguez et al. 2005).

The blocks were rectangular, with dimensions of $200 \mathrm{~mm}$ long by $100 \mathrm{~mm}$ wide by $80 \mathrm{~mm}$ deep, with vertically drilled slots from the top surface to the base to allow infiltration. Four symmetrical shapes of concrete block were designed that would provide drainage through their slots. Figure 3 shows the four blocks and their infiltration areas.

The blocks were developed in cooperation with Bloques Montserrat S.L., an established pre-cast concrete products manufacturer in Santander (Spain). They were manufactured by pouring concrete into purpose-built moulds and curing in air.

\section{Test procedure}

The hydraulic performance of the four paving blocks was investigated under varying slopes and silt contents. The samples were tested using four gradients: $0 \%, 2 \%$, $5 \%$ and $10 \%$. The clogging influence was assessed by testing each sample with three contents of silt as follows:

- No silt content.

- 500 grams of silt added: the silt distributed equally through the gaps between the blocks, in a single filling and compaction equivalent to $2 \mathrm{~kg} / \mathrm{m}^{2}$.

- Full of silt: the silt was added manually and handcompacted.

The selection of these three different silt amounts allowed comparison of hydraulic performance under equal silt contents $(0 \mathrm{~g}$ and $500 \mathrm{~g})$, as well as determining which of the blocks had a greater sedimentation tolerance and their behaviour under fully clogged conditions. 

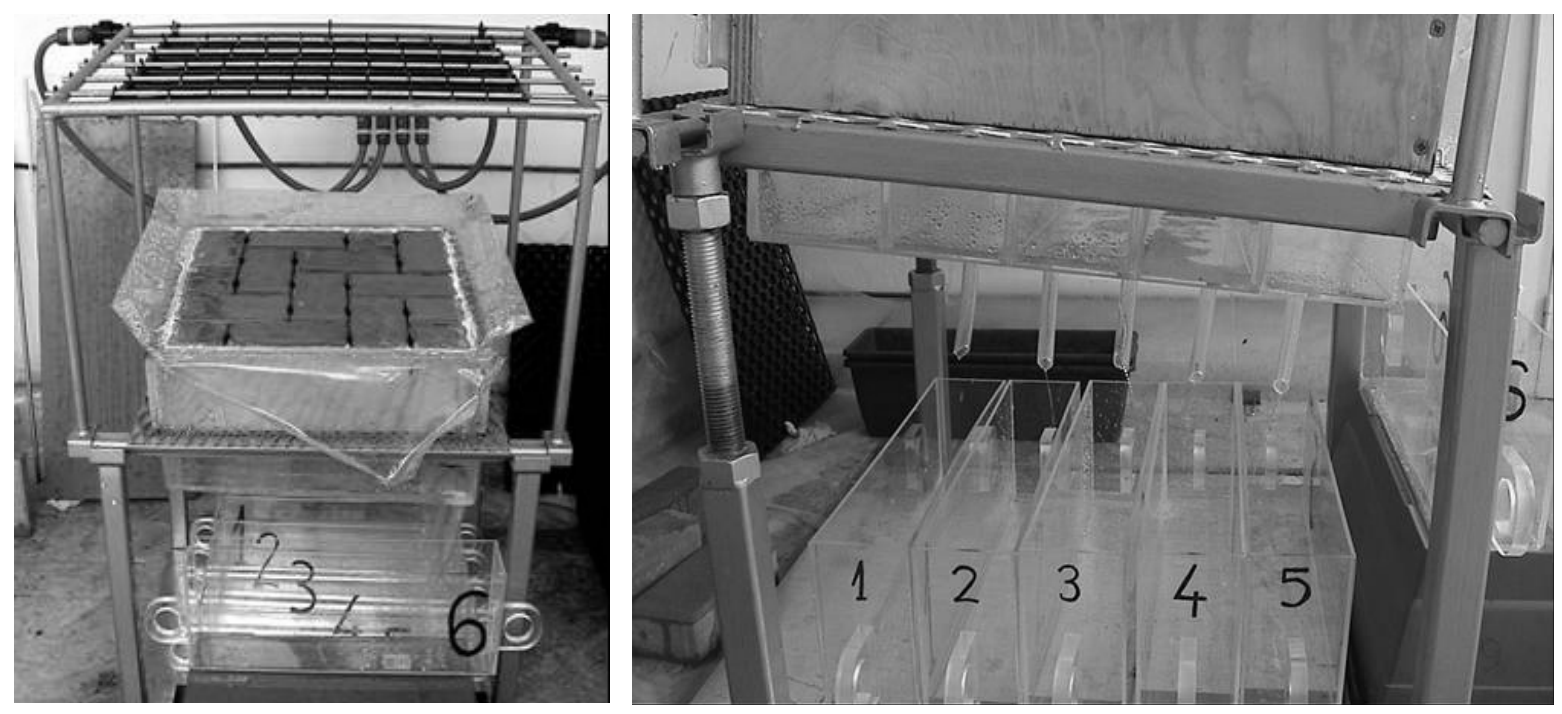

Figure 1. Test apparatus with rain simulator, and detail of the slope-adjustable frame - with the five chambers used to collect the infiltrated water, and the sixth for runoff collection
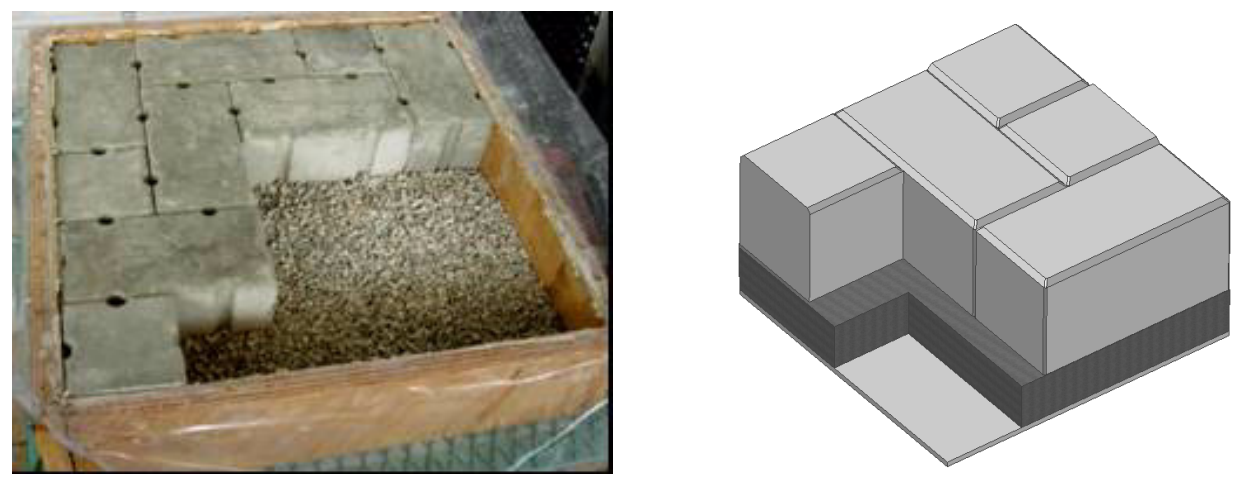

Figure 2. Construction of permeable pavement samples with geotextile, aggregate and concrete blocks

\begin{tabular}{|l|c|c|c|c|}
\hline Concrete block & B1 & B2 & B3 & B4 \\
\hline Slot shape & Rhomboidal & Circular & 603.2 \\
\hline $\begin{array}{l}\text { Infiltration area } \\
\left(\mathrm{mm}^{2}\right)\end{array}$ & 600.0 & 600.0 & \\
\hline
\end{tabular}

Figure 3. The four geometries of blocks tested, with their corresponding gap shape and infiltration area 


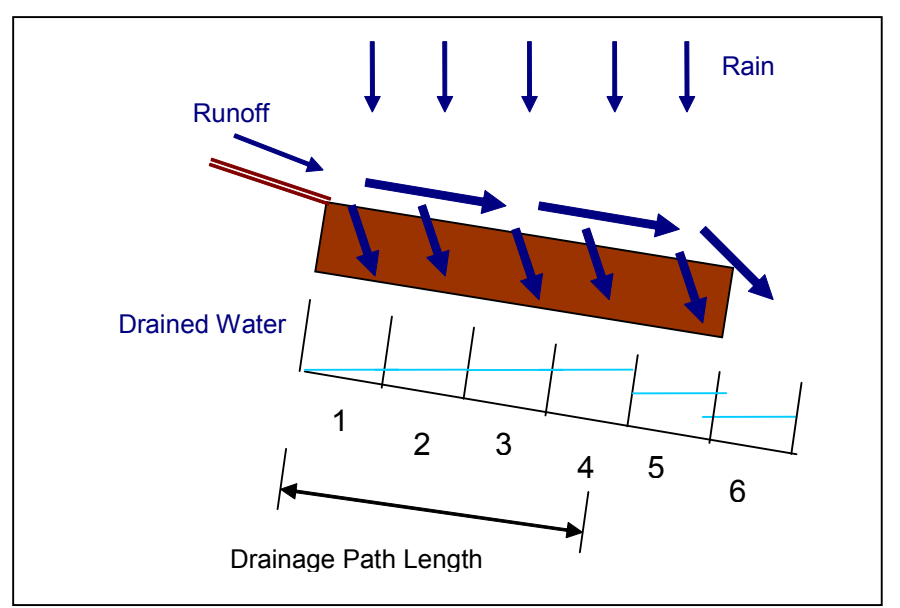

Figure 4. Drainage path length in a permeable pavement sample

The silt selected for the tests was crushed construction debris containing concrete, bricks, glass, metal and wood with an organic matter content of $3 \%$, by the potassium dichromate method, and $5 \%$ by ignition loss of the material under $2 \mathrm{~mm}$ diameter. The particle size distribution was that used by Rodríguez et al. (2005). This silt was selected because it represents the worst situation possible: a construction site or a demolition site near the permeable pavement.

To fully clog the samples, 1000 grams of silt were prepared. Gaps were overfilled and hand-compacted. Excess silt was brushed along the block edges to ensure edge clogging, and excess silt in the pavement surface was collected and stored.

The remaining silt was sieved to determine the particle sizes that did not enter the samples. Knowing the particle size prepared, and the particle size not within the pavement, by direct subtraction per particle size, the size distribution that clogged each surface was determined.

The water inputs were constant in all experiments, in order to compare the response of the different permeable pavements with an easily repeatable simulation of rainfall. The samples received a direct rain of $50 \mathrm{~mm} / \mathrm{h}$ intensity, produced by the five sprinkler lines, and runoff produced by an imaginary equivalent impermeable area above the sample subjected to the same rain intensity of $50 \mathrm{~mm} / \mathrm{h}$ (Rodríguez et al. 2005).

Having undertaken trial tests for apparatus calibration, one set of comparison tests was carried out with each block. The two paving blocks that performed best were selected for further comparison tests. Data from these tests indicated which was the optimum block geometry of the four tested.

The same sequence was applied for each of the silt contents. Before the measurement period commenced, the sample was left under the $50 \mathrm{~mm} / \mathrm{h}$ rain and runoff for ten minutes of wetting, allowing water to enter through the gaps in the blocks and wet the geotextile and base.

The measurement period was 30 minutes, set up as follows:

- 20 minutes of rain produced by the sprinklers and curtain rain;

- ten minutes of no rain, to allow water within the sample to drain to the filter chambers or the runoff chamber.

The volume of water collected in each of the six chambers during these 30 minutes was measured and the slope adjusted, repeating the sequence again until the last slope was tested.

\section{RESULTS AND DISCUSSION}

The results are presented as they were obtained in the laboratory: a first series with all four blocks - to select two best-performing blocks, and a second series with two replicas of each of these two best-performing blocks. 


\section{First series}

Table 1 presents the results obtained after testing the four geometries. For each gradient, the total volume collected in the six chambers is indicated $\left(\mathrm{V}_{\mathrm{T}}(\mathrm{L})\right)$. The percentage of volume filtered (FILTER (\%)) is the sum of the volumes collected in chambers 1 to 5 , as a percentage of the total volume collected in all chambers. The percentage of runoff is the remainder (RUNOFF $(\%))$.

The trend observed in all blocks is of reducing infiltration with increasing gradients, but if no silt is accumulated in the gaps, then the four blocks under $50 \mathrm{~mm} /$ $\mathrm{h}$ rain and an equivalent runoff can infiltrate more than $90 \%$ of the water received, even if placed in a $10 \%$ gradient. The difference in this unclogged state is minor; the performance of the different geometrical layout does not greatly affect the behaviour of the blocks if the gaps are clean.

The addition of 500 grams of construction debris silt, evenly distributed along the pavement surface, reduces the infiltration capacity, although it has a greater effect on the infiltration capacities of blocks 2 and 3 (circular gap and square gap). Also the increasing gradient increases the amount of runoff.

In the final test the samples were completely clogged using the method of application specified. The mass of silt needed to fill the gaps varied, depending on the geometry of the slots, and it can be seen that the longer and narrower slots (blocks 1 and 4) used a greater mass of silt than the shorter and wider slots (blocks 2 and 3). Runoff increases greatly from a minimum gradient of $2 \%$ if the samples are clogged.

This first series of tests shows that under equal conditions (no silt and $500 \mathrm{~g}$ applied) the two bestperforming blocks are block 1 (rhomboidal slots) and block 4 (elliptical slots), with both showing a considerable difference when semi-clogged (500 g of silt applied). This could be because the slot shape is longer than that of the other blocks.

\section{Second series}

Two further sets of hydraulic performance tests were carried out with replicas of blocks 1 and 4. The aim of this second series of tests was to check result reliability, as well as to obtain an average result value per block, slope and mass content. Table 2 displays the results of these tests.
The percentages of runoff for both blocks, when no silt is applied, are within a similar range of values. Block 4 (elliptical) has a slightly lower infiltration capacity for $5 \%$ and $10 \%$ gradients. The trends followed are related to the increasing gradient, and the largest difference is of $1 \%$ at the $10 \%$ gradient; therefore the blocks follow a similar pattern when no silt is present.

With $500 \mathrm{~g}$ of added silt, both blocks follow a similar trend. In this case, the differences between block 1 and block 4 start at a $\%$ gradient, having differences of the order of $3 \%$. At the steepest slope, block 4 performs slightly worse than block 1 . The infiltration capacities of both blocks remain at a minimum of $85 \%$ of drainage capacity when semi-clogged and subjected to $50 \mathrm{~mm} / \mathrm{h}$ of vertical rain plus an equivalent runoff.

The data in clogged conditions confirm the great reduction in infiltration capacity measured in the first series of results for these two blocks. The amount of runoff increases significantly when setting the clogged sample to a minimum slope of $2 \%$. The amounts of silt remain considerably higher than the silt contents required to clog the two discarded geometries (circular and square gap blocks), having similar clogging masses to the masses in the first series of infiltration capacity tests.

The results obtained for the two replicated blocks are consistent when compared with each other. The values are similar to those of the previous series, and the reliability of results and apparatus can be assured. However, some results of the data in the first series of infiltration capacity tests deviate from the replicas. These differences in results are inconclusive.

\section{Drainage path analysis}

The drainage path of a pervious pavement is the distance travelled by the surface flow from the beginning of the permeable surface to where it drains. The drainage path can be located by identifying where the input water is collected after infiltration through the permeable pavement sample (Figure 4).

\section{No silt accumulated}

At $0 \%$ slope, most of the water is accumulated in chambers 1 and 3 (Figure 5). With no accumulated silt, the hydraulic performance of the pavement blocks is 
Land Contamination \& Reclamation / Volume 15 / Number 3 / 2007

Table 1. Percentage distribution of collected water for each block, varying the silt content $\left(M_{\text {silt }}\right)$ and slope: first series

\begin{tabular}{|c|c|c|c|c|c|}
\hline$M_{\text {SILT }}(g)$ & BLOCK & SLOPE (\%) & $\mathrm{V}_{\mathrm{T}}(\mathrm{L})$ & FILTER (\%) & RUNOFF (\%) \\
\hline \multirow{16}{*}{0} & \multirow{4}{*}{ B1 } & 0 & 7.270 & 99.9 & 0.1 \\
\hline & & 2 & 7.665 & 99.0 & 1.0 \\
\hline & & 5 & 8.289 & 96.9 & 3.1 \\
\hline & & 10 & 8.608 & 95.4 & 4.6 \\
\hline & \multirow{4}{*}{ B2 } & 0 & 7.714 & 99.7 & 0.3 \\
\hline & & 2 & 8.257 & 98.6 & 1.4 \\
\hline & & 5 & 8.095 & 95.3 & 4.7 \\
\hline & & 10 & 8.284 & 92.9 & 7.1 \\
\hline & \multirow{4}{*}{ B3 } & 0 & 7.383 & 99.7 & 0.3 \\
\hline & & 2 & 10.147 & 96.7 & 3.3 \\
\hline & & 5 & 7.655 & 94.3 & 5.7 \\
\hline & & 10 & 8.417 & 91.4 & 8.6 \\
\hline & \multirow{4}{*}{ B4 } & 0 & 7.515 & 99.7 & 0.3 \\
\hline & & 2 & 7.604 & 99.5 & 0.5 \\
\hline & & 5 & 7.251 & 98.8 & 1.2 \\
\hline & & 10 & 8.889 & 93.6 & 6.4 \\
\hline \multirow{16}{*}{500} & \multirow{4}{*}{ B1 } & 0 & 5.527 & 99.9 & 0.1 \\
\hline & & 2 & 7.145 & 98.7 & 1.3 \\
\hline & & 5 & 7.017 & 97.9 & 2.1 \\
\hline & & 10 & 8.545 & 97.0 & 3.0 \\
\hline & \multirow{4}{*}{ B2 } & 0 & 8.381 & 99.5 & 0.5 \\
\hline & & 2 & 8.343 & 97.2 & 2.8 \\
\hline & & 5 & 8.209 & 91.4 & 8.6 \\
\hline & & 10 & 7.969 & 80.2 & 19.8 \\
\hline & \multirow{4}{*}{ B3 } & 0 & 7.480 & 99.8 & 0.2 \\
\hline & & 2 & 8.439 & 94.2 & 5.8 \\
\hline & & 5 & 8.135 & 91.2 & 8.8 \\
\hline & & 10 & 8.524 & 78.9 & 21.1 \\
\hline & \multirow{4}{*}{ B4 } & 0 & 7.472 & 99.9 & 0.1 \\
\hline & & 2 & 8.767 & 95.9 & 4.1 \\
\hline & & 5 & 8.367 & 94.0 & 6.0 \\
\hline & & 10 & 7.430 & 89.3 & 10.7 \\
\hline \multirow{4}{*}{791} & \multirow{4}{*}{ B1 } & 0 & 7.548 & 100.0 & 0.0 \\
\hline & & 2 & 7.680 & 85.5 & 14.5 \\
\hline & & 5 & 7.760 & 27.0 & 73.0 \\
\hline & & 10 & 9.156 & 16.2 & 83.8 \\
\hline \multirow{4}{*}{665} & \multirow{4}{*}{ B2 } & 0 & 8.302 & 99.1 & 0.9 \\
\hline & & 2 & 7.827 & 82.8 & 17.2 \\
\hline & & 5 & 7.913 & 61.0 & 39.0 \\
\hline & & 10 & 8.829 & 61.5 & 38.5 \\
\hline \multirow{4}{*}{620} & \multirow{4}{*}{ B3 } & 0 & 8.070 & 99.9 & 0.1 \\
\hline & & 2 & 8.895 & 56.0 & 44.0 \\
\hline & & 5 & 8.113 & 32.4 & 67.6 \\
\hline & & 10 & 7.783 & 23.0 & 77.0 \\
\hline \multirow{4}{*}{797} & \multirow{4}{*}{ B4 } & 0 & 7.112 & 98.8 & 1.2 \\
\hline & & 2 & 7.947 & 59.6 & 40.4 \\
\hline & & 5 & 8.420 & 45.5 & 54.5 \\
\hline & & 10 & 8.356 & 32.0 & 68.0 \\
\hline
\end{tabular}


Figure 5. Distribution of the volumes of drained water collected in the different chambers with no silt addition to the permeable surface

Figure 6. Distribution of the volumes of drained water collected in the different chambers with semi-clogged permeable surface

Figure 7. Distribution of the volumes of drained water collected in the different chambers with fully clogged permeable surface
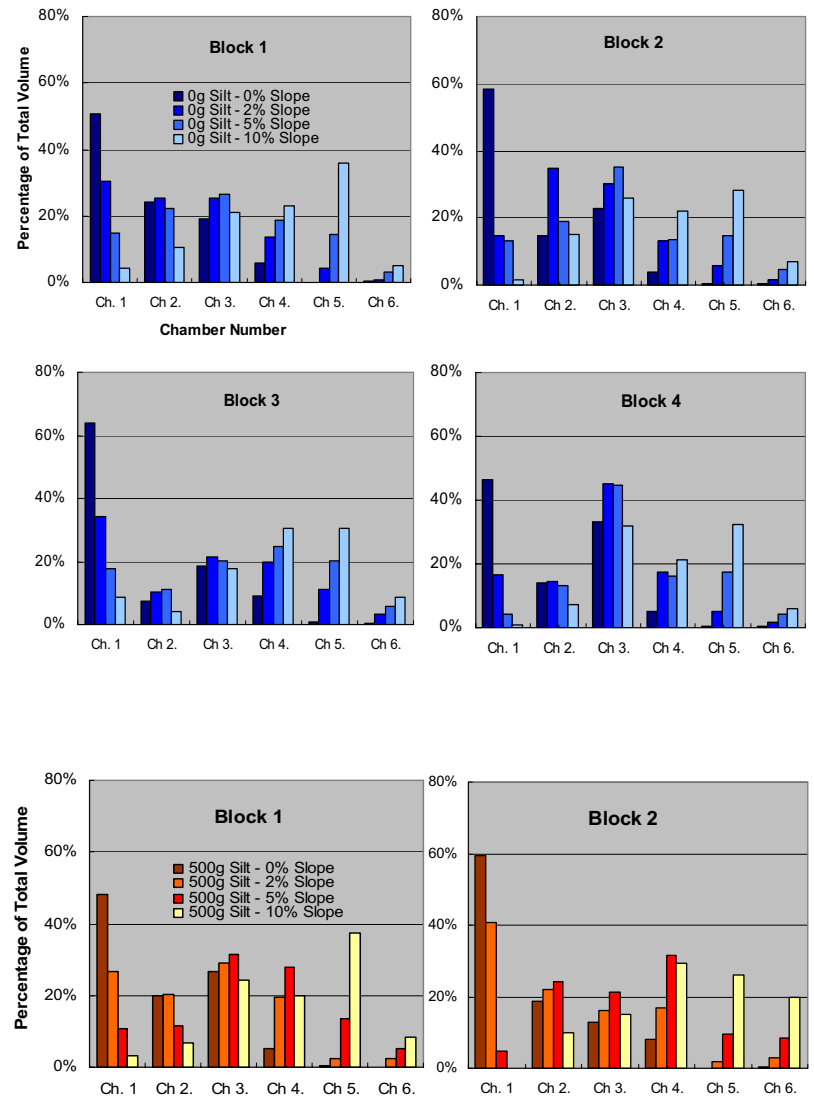
Chamber Numbe
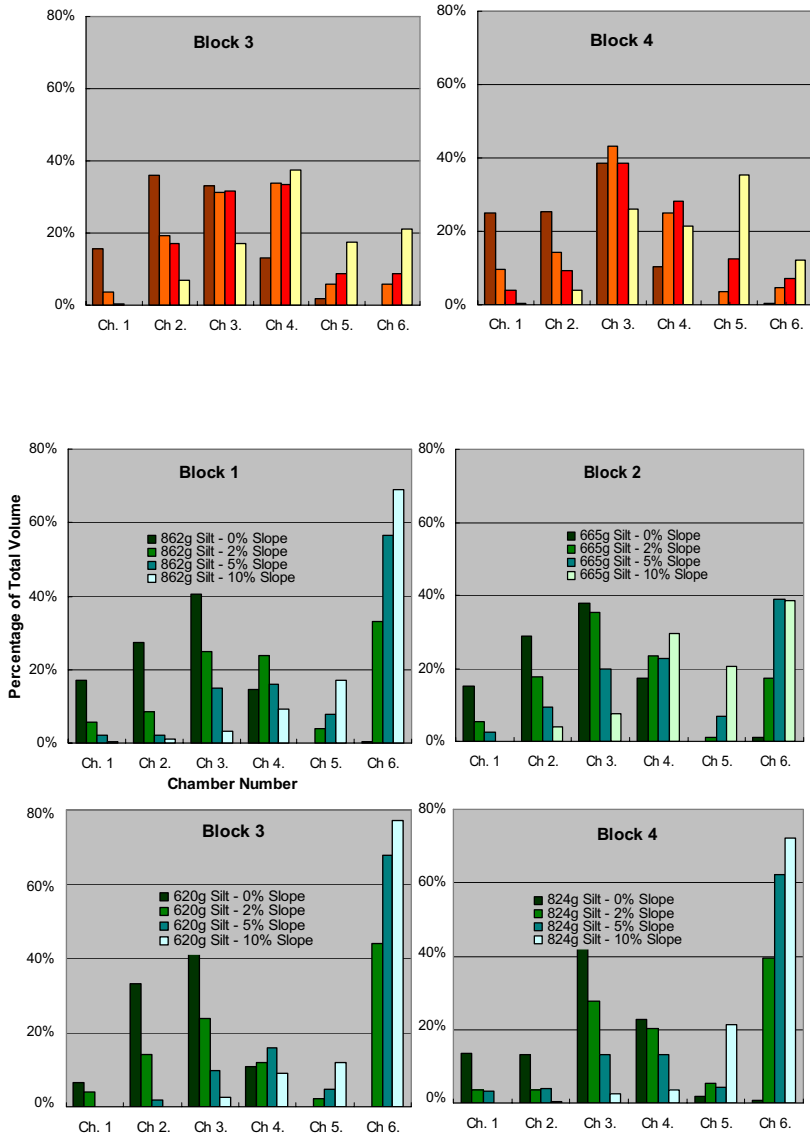
similar. Over $70 \%$ of the water was collected in the first three chambers.

At a $2 \%$ slope, the percentages of total volume in chamber 1 decrease significantly, increasing in the other chambers. Most of the volume is accumulated in chambers 2, 3 and 4. The amounts of water collected in chambers 5 and 6 increase, but not as significantly as chamber 4 , which, in all cases, has double the percentage that it has at a $0 \%$ slope.

At $5 \%$ inclination, the percentage in chamber 1 continues to decrease, containing less than $10 \%$ of the total volume collected for all blocks. More than $60 \%$ of the water is collected in chambers 2, 3 and 4.

At $10 \%$ slope, most of the water is collected in chambers 3, 4 and 5. Therefore, although the percentage collected in chamber 6 does not increase dramatically, measurements show that the change in slope does affect the length of the drainage path of the rain and the runoff, thus varying the position of the drainage beneath the pavement structure.

\section{Semi-clogged pavement}

The four with the semi-clogged pavements drain most of the input rain and runoff along the first half of the pavement at $0 \%$ gradient (Figure 6). Blocks 1 and 2 gather at least $50 \%$ of all the water collected in chamber 1 . On the other hand, blocks 3 and 4 do not show a distinct collecting peak.

At a gradient of $2 \%$, the pavements drain most of the input water to chambers $1,2,3$ and 4 . There is no significant peak for any block at this slope. At a $10 \%$ gradient, most of the water collected was conveyed in chambers 3, 4, 5 and 6 . The maximum percentages at this slope are in chamber 4 for blocks 2 and 3, and in chamber 5 in blocks 1 and 4 .

If the percentages carried by each chamber are examined, it can be seen that the different blocks behave differently. This could be due to differences in the amounts of silt in each gap as well as the level of compaction.

\section{Fully clogged pavement}

With fully clogged pavements and a $0 \%$ slope, water accumulates in chambers 1, 2 and 3, leaving chambers 5 and 6 with residual amounts (Figure 7). Chamber 3 is clearly identifiable as having the peak percentage for all blocks at this slope.
The gentle increase in slope from a level pavement to a $2 \%$ slope reduces the percentages filtered to the first three chambers, and significantly increases the ratio of runoff. This effect is clear if block 3 is examined. At $2 \%$ gradients there are two peaks of accumulation: chamber 3 and chamber 6 .

A further decrease in percentages filtered to chambers 1,2 and 3 occurs when increasing the gradient to $5 \%$. At this slope, chamber 6 shows a distinct peak of accumulation. In all blocks, the percentage conveyed to chamber 5 is less than $5 \%$.

\section{Selection of optimum block geometry}

Residual runoff is of great importance in selecting the best block geometry, but there are also other important criteria. Factors such as clogging mass, particle size acceptance, aesthetic implications and functionality must also be taken into account.

The results obtained in the tests carried out with block 4 are reasonably consistent. Block 1 showed greater variance of results when comparing the tests in the first series and the second series.

Both blocks can filter over $80 \%$ of the input rain and runoff even in semi-clogged conditions. The block-toblock contact surface provided by block 1 is lower than block 4 , and block 4 has a shorter and slightly narrower slot that can limit the size of particles entering the pavement structure. Assessing these and other factors in addition to its hydraulic performance, block 4 was selected as the one with the optimum block geometry from amongst those tested.

\section{CONCLUSIONS}

The comparative analysis of the block shapes showed that:

- Although the infiltration areas of all the blocks were equivalent, the blocks with longer and narrower slots performed at higher levels than the blocks with shorter and wider gaps.

- The amount and particle sizes of the silt affect the hydraulic performance.

- The reduction in infiltration capacity increases dramatically when the pavement surface is fully clogged, and when this is combined with an increasing gradient. 
The influence of paving-block shape on the infiltration capacity of permeable paving

Table 2. Percentage distribution of collected water for each block, varying the silt content $\left(\mathbf{M}_{\text {sitt }}\right)$ and slope: second series (replicas of blocks 1 and 4 )

\begin{tabular}{|c|c|c|c|c|c|}
\hline$M_{\text {SILT }}(g)$ & BLOCK & SLOPE (\%) & $\mathbf{V}_{\mathrm{T}}(\mathrm{L})$ & FILTER (\%) & RUNOFF (\%) \\
\hline \multirow{16}{*}{0} & \multirow{8}{*}{ B1 } & 0 & 6.727 & 100.0 & 0.0 \\
\hline & & 2 & 7.594 & 99.3 & 0.7 \\
\hline & & 5 & 8.323 & 96.4 & 3.6 \\
\hline & & 10 & 7.609 & 94.8 & 5.2 \\
\hline & & 0 & 8.811 & 99.5 & 0.5 \\
\hline & & 2 & 9.603 & 99.4 & 0.6 \\
\hline & & 5 & 8.766 & 97.3 & 2.7 \\
\hline & & 10 & 9.162 & 94.7 & 5.3 \\
\hline & \multirow{8}{*}{ B4 } & 0 & 6.170 & 99.6 & 0.4 \\
\hline & & 2 & 6.184 & 98.5 & 1.5 \\
\hline & & 5 & 8.012 & 95.7 & 4.3 \\
\hline & & 10 & 8.176 & 93.8 & 6.2 \\
\hline & & 0 & 8.516 & 99.4 & 0.6 \\
\hline & & 2 & 8.283 & 98.3 & 1.7 \\
\hline & & 5 & 8.538 & 96.2 & 3.8 \\
\hline & & 10 & 8.526 & 93.8 & 6.2 \\
\hline \multirow{16}{*}{500} & \multirow{8}{*}{ B1 } & $\overline{0}$ & 7.502 & 99.7 & 0.3 \\
\hline & & 2 & 8.559 & 98.2 & 1.8 \\
\hline & & 5 & 8.733 & 95.2 & 4.8 \\
\hline & & 10 & 8.157 & 92.2 & 7.8 \\
\hline & & 0 & 7.494 & 100.0 & 0.0 \\
\hline & & 2 & 8.473 & 97.3 & 2.7 \\
\hline & & 5 & 7.860 & 94.8 & 5.2 \\
\hline & & 10 & 7.631 & 91.2 & 8.8 \\
\hline & \multirow{8}{*}{ B4 } & 0 & 8.338 & 99.6 & 0.4 \\
\hline & & 2 & 7.635 & 95.0 & 5.0 \\
\hline & & 5 & 7.289 & 92.4 & 7.6 \\
\hline & & 10 & 7.454 & 87.5 & 12.5 \\
\hline & & 0 & 8.528 & 99.8 & 0.2 \\
\hline & & 2 & 8.814 & 95.5 & 4.5 \\
\hline & & 5 & 8.394 & 91.7 & 8.3 \\
\hline & & 10 & 8.137 & 86.4 & 13.6 \\
\hline \multirow{4}{*}{870} & \multirow{8}{*}{ B1 } & 0 & 8.061 & 99.8 & 0.2 \\
\hline & & 2 & 7.713 & 58.7 & 41.3 \\
\hline & & 5 & 8.447 & 41.3 & 58.7 \\
\hline & & 10 & 8.089 & 22.7 & 77.3 \\
\hline \multirow{4}{*}{924} & & 0 & 9.457 & 99.2 & 0.8 \\
\hline & & 2 & 8.782 & 74.9 & 25.1 \\
\hline & & 5 & 8.577 & 45.4 & 54.6 \\
\hline & & 10 & 9.115 & 39.1 & 60.9 \\
\hline \multirow{4}{*}{821} & \multirow{8}{*}{ B4 } & 0 & 8.418 & 99.3 & 0.7 \\
\hline & & 2 & 7.712 & 61.1 & 38.9 \\
\hline & & 5 & 8.274 & 36.5 & 63.5 \\
\hline & & 10 & 8.371 & 25.6 & 74.4 \\
\hline \multirow{4}{*}{860} & & 0 & 8.976 & 99.5 & 0.5 \\
\hline & & 2 & 7.829 & 60.9 & 39.1 \\
\hline & & 5 & 8.253 & 30.8 & 69.2 \\
\hline & & 10 & 8.306 & 25.6 & 74.5 \\
\hline
\end{tabular}


- When the slope increases, the drainage path along the pavement also increases. This increase is greater for a slope increasing from $2 \%$ to $5 \%$ than from $5 \%$ to $10 \%$.

\section{ACKNOWLEDGEMENTS}

This work was part of Nelson González-Angullo's final project for the MSc in European Construction, and is part of the research project 'Development of new structures of pavements for the biodegradation of hydrocarbons (FIDICA)' financed by the Spanish Ministry of Science and Technology with funds from the PGE (General Budget of the State) and the FEDER (European Funds for Regional Development), reference REN2003-05278/TECNO.

We would like to thank Coventry University for their collaboration, and also the following companies: Formpave Ltd., Bloques Montserrat SL, Fibertex Nonwovens and Danosa, and KPC Consultancy Ltd for providing additional services.

\section{REFERENCES}

Davies, J.W., Pratt, C.J. and Scott, M.A. (2002) Laboratory study of permeable pavement systems to support hydraulic modelling. In: Proceedings of the 9th International Conference on Urban Drainage, Portland, Oregon. American Society of Civil Engineers

Dierkes, C., Kuhlmann, L., Kandasamy, J. and Angelis, G. (2002) Pollution retention capability and maintenance of permeable pavements, pp. 2-6. In: Proceedings of the Ninth
International Conference on Urban Drainage, Portland, Oregon. American Society of Civil Engineers

Novotny, V. and Olem, H. (1994) Water Quality. Prevention, Identification and Management of Diffuse Pollution. Van Nostrand Reinhold, New York

Pratt, C.J. (1997) Design guidelines for porous/permeable pavements. In Proc. of Conference on Sustaining Urban Water Resources in the 21st Century, Malmo, Sweden. American Society of Civil Engineers

Pratt, C.J. (2003) Application of geosynthetics in sustainable drainage systems. 1st International Geosynthetics Society, UK Chapter 'Geosynthetics: Protecting the Environment', Loughborough, 17 June. Thomas Telford

Pratt, C.J., Wilson, S. and Cooper, P. (2002) Source Control Using Constructed Pervious Surfaces. Hydraulic, Structural and Water Quality Performance Issues. CIRIA C582, RP637. CIRIA, London

Rodríguez, J., Castro, D., Calzada, M.A. and Davies, J.W. (2005) Pervious pavement research in Spain: structural and hydraulic issues. In: Proceedings of the 10th International Conference on Urban Drainage (10ICUD)

Rommel, M., Rus, M., Argue, J., Johnston, L. and Pezzaniti, D. (2001) Carpark with 1 to 1 (impervious/permeable) paving: performance of 'Formpave' blocks. In: Novatech International Conference on Innovative Technologies in Urban Storm Drainage, Vol II, 25-27 July 2001, pp. 807-814. Lyon, France

Schueler, T.R. (1987) Controlling Urban Runoff. A Practical Manual for Planning and Designing Urban BMPs. Metropolitan Washington Water Resources Planning Board 